\title{
Correction to: An Empirical Model for River Ecological Management with Uncertainty Evaluation
}

\author{
Francesca Palomba ${ }^{1}$ - Giorgio Cesari ${ }^{2} \cdot$ Remo Pelillo $^{3}$. \\ Andrea Petroselli ${ }^{4}$
}

Published online: 25 November 2017

(C) Springer Science+Business Media B.V., part of Springer Nature 2017

\section{Correction to: Water Resour Manage \\ https://doi.org/10.1007/s11269-017-1845-9}

Due to an oversight, the author names were incorrectly captured in the original publication. The first and last names of the authors were inverted. The correct presentation of the author names is shown above.

The original article was corrected.

The online version of the original article can be found at https://doi.org/10.1007/s11269-017-1845-9

\author{
Andrea Petroselli \\ petro@unitus.it \\ Francesca Palomba \\ palomba@unitus.it \\ Giorgio Cesari \\ gio.cesari@libero.it \\ Remo Pelillo \\ remo.pelillo@abtevere.it
}

1 Department of Agriculture and Forestry Sciences (DAFNE), Tuscia University, Via San Camillo De Lellis snc, 01100 Viterbo, Italy

2 Central Italy Section of Italian Hydrotechnical Association, Rome, Italy

3 Tiber River Basin Authority (hereafter Central Apennines District Authority), Via Monzambano 10, 00185 Rome, Italy

4 Department of Economics, Engineering, Society and Business Organization (DEIM), Tuscia University, Via San Camillo De Lellis snc, 01100 Viterbo, VT, Italy 